\title{
Komplikasi Ibu Hamil dengan Penyakit Jantung
}

\author{
Purwoko \\ Bagian Anestesiologi dan Terapi Intensif \\ Fakultas Kedokteran Universitas Sebelas Maret-RSUD. Dr. Moewardi
}

\begin{abstract}
Abstrak
Penyebab kematian ibu hamil pada operasi non kardiak 25 - $50 \%$ adalah komplikasi kardiovaskuler seperti infark, miokard, edema paru, gagal jantung, aritmia dan tromboemboli perioperatif. Prediktor risiko komplikasi kardiovaskuler pada maternal dan neonatal sangat penting dilakukan agar risiko kematian dapat ditekan semaksimal mungkin. Prediktor mortalitas pada maternal dengan penyakit jantung seperti atrial septal defect (ASD), ventricular septal defect (VSD), persisten ductus aeteiousus (PDA) dengan hipertensi pulmonal, ectopic beat, atrial ventrikuler yang tidak respon terapi, stenosis pulmonal berat dan prolap katub mitral. Tujuan anestesi pada kehamilan dan kelahiran spontan antara lain mengoptimalkan fungsi kardiovaskuler dan respirasi dengan memanipulasi hemodinamik sesuai target dan pemilihan teknik anestesi yang sesuai kondisi pasien. Prinsip dari manajemen anestesi adalah menjaga sirkulasi uteroplasenta dengan mencegah kompresi aorto cava, meminimalkan blok simpatis dan menjaga kecukupan cairan serta monitoring ketat pada ibu dan janin.
\end{abstract}

Kata kunci: komplikasi kardiovaskuler, ibu hamil, anestesi, monitoring

\section{Complications of Maternal Heart Disease}

\begin{abstract}
Causes of death of pregnant in 25-50\% of non-cardiac surgery cases are cardiovascular complications such as myocardial infarction, pulmonary edema, heart failure, arrhythmias, and perioperative thromboembolism. Predictors of high-risk cardiovascular complications in maternal and neonatal are crucial to reducing the mortality rate. Predictors of high-risk maternal mortality associated with cardiovascular disease are atrial septal defect (ASD), ventricular septal defect (VSD), persisten ductus aeteiousus (PDA) with pulmonary hypertension, ectopic beats, unresponsive atrial ventricular to therapy, severe pulmonary stenosis, and mitral valve prolapse. The goals of anesthesia in pregnancy and spontaneous delivery include optimizing cardiovascular and respiratory function by manipulating hemodynamics according to targets and selecting anesthetic techniques according to the patient's condition. The principle of anesthetic management is to protect the uteroplacental by preventing aortic cava compression, minimizing sympathetic block and maintaining adequate fluid intake, and monitoring the mother and fetus closely.
\end{abstract}

Key words: cardiovascular complications, pregnant women, anesthesia, monitoring 


\section{Pendahuluan}

Prevalensi penyakit jantung kongenital atau penyakit jantung bawaan (PJB) di Eropah telah di ketahui sebesar 8.3 per 1000 kelahiran hidup, dengan 3 tipe kelainan terbanyak berupa ventricular septal defect (VSD) 2.6 per 1000 kelahiran hidup, atrial septal defect (ASD) 1.6 per 1000 kelahiran hidup dan persisten ductus arteriosus (PDA) 0.9 per 1000 kelahiran hidup. Sebelum tahun 1950, penderita penyakit jantung bawaan pada umumnya meninggal dunia di saat awal kehidupannya. Dengan adanya kemajuan di bidang kedokteran, terutama dalam bidang bedah toraks kardiovaskuler, maka harapan hidup penderita penyakit jantung bawaan menjadi lebih baik. Di samping kemajuan di bidang bedah toraks kardiovaskuler, juga terjadi kemajuan di bidang anestesi, perawatan intensif, pediatri dan kardiologi yang memungkinkan pasien dengan penyakit jantung bawaan bisa bertahan hidup hingga dewasa tampa di koreksi penyakitnya. ${ }^{1,2}$

Kehamilan telah di ketahui menyebabkan stres hemodinamik pada jantung dan ini dapat mengakibatkan komplikasi ibu dan janin. Sebagian wanita dengan penyakit jantung bawaan mampu menjalani kehamilan dengan baik, tetai beberapa wanita dengan lesi jantung berisiko tinggi dan tidak akan mentolerir perubahan hemodinamik selama hamil. Wanita dengan PJB juga berkeinginan hamil sebagaimana wanita normal lainnya. Besarnya risiko kejadian di atas tergantung pada tipe dan berat ringannya PJB yang di derita wanita hamil tersebut. Pasien dengan PJB, memiliki tekanan dan volume pada ventrikel yang berlebihan dalam waktu yang lama selanjutnya terjadi dilatasi ventrikel dan hipertrofi miokard serta fibrosis. Aritmia supraventrikular lebih umum daripada aritmia ventrikel pada populasi pasien dengan PJB. Toleransi terhadap aritmia pada pasien dengan PJB adalah buruk, sehingga dapat mengakibatkan gangguan hemodinamik. Aritmia juga dapat meningkatkan risiko terjadi nya emboli. Maternal dengan PJB akan berpengaruh terhadap janin yang di kandung berupa hambatan pertumbuhan dalam kandungan dengan berat badan lahir rendah, peningkatan risiko kelahiran premature, peningkatan risiko keguguran atau kematian intrauterin serta peningkatan kematian perinatal. Oleh karena itu dokter harus menyadari potensi risiko bagi ibu baik selama dan setelah kehamilan, memikirkan risiko terhadap janin dan neonatus dan memikirkan risiko dan manfaat dari obat-obatan serta prosedur yang di gunakan selama kehamilan. Untuk wanita dengan kondisi jantung yang kompleks, lebih baik dilakukan manajemen perawatan selama hamil secara multidisiplin. ${ }^{3}$

\section{Perubahan Fisiologis pada saat Kehamilan}

Perubahan kardiovaskuler dan respirasi yang terjadi selama kehamilan dan periode peripartum dapat memperngaruhi kondisi maternal dengan penyakit jantung. Berikut adalah beberapa perubahan kardiovaskuler dan respiratori pada wanita hamil dan wanita tidak hamil.

\section{System Respirasi}

Terjadi peningkatan volume semenit dan konsumsi oksigen pada saat kehamilan, disertai dengan hiperventilasi yang di sebabkan oleh efek progesteron pada system saraf pusat. Peningkatan ventilasi semenit menyebabkan respirasi alkalosis yang ringan.

\section{Volume Darah}

Pada saat cukup bulan volume plasma lebih tinggi $40-50 \%$ daripada saat sebelum hamil, dengan meningkatnya volume plasma melebihi peningkatan eritrosit (RBC) (20-30\%) hal ini menyebabkan terjadinya anemia fisiologis karena dilusi yang dapat di terapi dengan pemberian iron per oral.

\section{Cardiac Output}

Cardiac output mulai meningkat pada saat usia kehamilan 10 minggu yang terus bertambah dan mencapai puncak $30-50 \%$ dari baseline pada minggu ke 32 usia gestasi. Penelitian menyatakan adanya penurunan signifikan dari cardiac output pada masa akhir kehamilan apabila pasien di posisikan supine yang di sebabkan oleh kompresi aorta dan vena cava. Sedang kan pada posisi lateral decubitus tidak di temukan penurunan dari cardiac output pada wanita hamil hal ini di sebabkan venous return 
yang tetap terjaga. Peningkatan cardiac output disebabkan oleh meningkatnya stroke volume pada awal kehamilan dan pada akhir kehamilan cardiac output di jaga oleh adanya peningkatan laju jantung. Di temukan peningkatan endogenous catecholamine pada saat proses kelahiran yang menyebabkan inotropik positif dan kronotropik dari respon. miokardium. Peningkatan left ventricular end diastolic volume (LVEDP) yang di sebabkan oleh peningkatan volume plasma yang kemudian meningkatkan kontraktilitas miokardium dan stroke volume.

\section{Proses Kelahiran}

Peningkatan laju jantung yang di sebabkan oleh nyeri saat mengejan dan peningkatan stroke volume yang di sebabkan oleh venous return yang bertambah dari kontraksi dapat meningkatkan cardiac output sebesar $20-50 \% .^{4-6}$

\section{Komplikasi Maternal pada Kehamilan dengan Penyakit Jantung Kongenital}

Penyebab kematian ibu hamil pada operasi non kardiak $25-50 \%$ karena ada nya komplikasi kardiovaskuler. Infark miokard, oedema paru, gagal jantung, aritmia dan tromboemboli perioperatif sering muncul pada pasien dengan penyakit penyerta kardiovaskuler. Maternal dengan PJB di ketahui memiliki risiko komplikasi kardiovaskuler yang meningkat sebesar $20 \%$. Prediktor outcome pada maternal dengan penyakit kongenital di pengaruhi oleh beberapa faktor yang terdapat dalam tablel 1. Prediktor risiko komplikasi kardiovaskuler pada maternal yang di adopsi dari CARPREG Risk Score. Pada
CARPREG Risk Score yang merupakan prediktor risiko komplikasi kardiovaskuler pada maternal yang sangat popular dan di gunakan di berbagai penelitian. Faktor penyakit jantung penyulit pada tabel tersebut meliputi pasien dengan populasi penyakit jantung bawaan dan penyakit jantung acquired. Pada prediktor ini setiap poin meningkatkan risiko komplikasi kardiovaskuler pada maternal pasca kehamilan. Prediktor risiko ini di simpulkan berdasarkan kumpulan populasi pasien dengan berbagai tipe penyakit jantung yang telah di validasi melalui berbagai penelitian akan menyebabkan peningkatan risiko terjadinya komplikasi kardiovaskuler. Skoring ini telah di gunakan secara luas sebagai prediktor yang berharga walaupun dapat terjadi estimasi berlebihan dalam prosesnya. Dengan adanya prediktor risiko ini dapat digunakan oleh dokter sebagai panduan dalam edukasi, perencanaan, strategi dan prognosis dari maternal yang memiliki faktor penyakit di atas sebagai penyulit.

\section{Komplikasi Fetal dan Neonatal pada Maternal dengan Penyakit Jantung}

Komplikasi pada neonatus terjadi pada 20$28 \%$ pasien dengan penyakit jantung. Risiko keguguran dan aborsi terapeutik meningkat pada wanita dengan penyakit jantung. Risiko keturunan nya juga menderita penyakit jantung lebih tinggi pada maternal yang menderita PJB. Risiko keturunan mewarisi penyakit jantung di ketahui sebesar 3-5\% sedang pada populasi umum risikonya $1 \%$. Prediktor mortalitas fetal neonatal seperti terlihat dalam tabel 2 . Wanita dengan penyakit jantung kongenital

Tabel 1. Prediktor Risiko Komplikasi Kardiovaskuler pada Maternal (Studi CARPREG)

\begin{tabular}{|l|}
\hline $\begin{array}{l}\text { Riwayat gangguan jantung sebelumnya (gagal jantung, serangan iskemik transien, stroke sebelum } \\
\text { kehamilan atau aritmia) }\end{array}$ \\
\hline Fungsional NYHA kelas 2 atau sianosis \\
\hline Obstruksi jantung kiri ( area katup mitral $<2 \mathrm{~cm}$, area katup aorta $<1.5 \mathrm{~cm}$, peak gradient traktus outflow \\
LV $>30$ mmHg dari Echokardiografi) \\
\hline Reduksi fungsi sistolik ventrikel sistemik $(\mathrm{EF}<40 \%$ ) \\
\hline Skor resiko CARPREG : untuk setiap prediktor CARPREG yang muncul ditandai poin. Estimasi risiko, \\
komplikasi maternal kardiovaskular \\
$0: 5 \%$ \\
$1: 27 \%$ \\
$>1: 75 \%$
\end{tabular}


Tabel 2. Prediktor Kejadian Neonatal pada Ibu dengan Penyakit Jantung

1. NYHA Kelas $>$ II atau dengan Sianosis

2. Obstruksi jantung kiri pada kehamilan

3. Merokok selama kehamilan

4. Hamil kembar

5. Penggunaanantikoagulanoral selamakehamilan 6. Katup jantung buatan.

memiliki peningkatan risiko komplikasi janin dan bayi, seperti kelahiran preterm (10-20\%), persalinan premature (lahir $<37$ minggu usia kehamilan) dengan atau tanpa ketuban pecah dini $(20 \%)$, gangguan pertumbuhan $(8 \%)$, aborsi spontan (12\%) dan sindrom gangguan pernafasan (8\%). Outcome neonatal yang buruk dapat terjadi pada 30\% kasus. Kematian janin dan bayi secara keseluruhan adalah sekitar $4 \%$ yang merupakan peningkatan empat kali lipat di bandingkan dengan populasi umum. Konsumsi obat jantung pada maternal dapat mempengaruhi janin seperti ACE Inhibitor, warfarin, dan statin. ACE Inhibitor di ketahui memiliki efek teratogenic pada trimester pertama dan karena itu harus di hindari selama periode ini. Paparan pada trimester kedua dan ketiga dapat menyebabkan hipotensi janin dan menurunkan aliran darah ke ginjal pada janin. Tingkat komplikasi neonatal meningkat secara signifikan pada wanita dengan penyakit jantung sianotik apalagi jika $\mathrm{SpO}_{2}<85 \%$. Prediktor outcome neonatus yang buruk jika NYHA $>$ klas II, sianosis, obstruksi ventrikel kiri, perokok, umum ibu $<20$ tahun atau $>35$ tahun, multiple gestasional dan memakai antikoagulan selama masa kehamilan. ${ }^{7}$

\section{Prediktor Mortalitas dan Morbiditas pada Maternal dengan Penyakit Jantung}

WHO memodifikasi dan mengeluarkan pembagian klasifikasi dengan tujuan sebagai prediktor mortalitas dan morbiditas pada maternal dengan mengintegrasikan faktor-faktor risiko penyakit kardivaskuler dan penyulitnya. Secara umum prinsip dari klasifikasi yang di keluarkan oleh WHO adalah. Pada maternal dengan WHO kategori kelas 1, di temukan risiko yang sangat rendah dan prenatal check up dengan kardiologi pada saat kehamilan dapat dilakukan 1-2x pertemuan. Pada maternal WHO kategori kelas II, di temukan risiko rendah dan moderate, dimana prenatal check up dapat di lakukan setiap trimester. Pada maternal WHO kategori kelas III, di temukan risiko yang tinggi terhadap kardiovaskular komplikasi sehingga di sarankan prenatal check up setiap bulan atau 2 bulan sekali. Pada maternal WHO kategori kelas IV, di sarankan untuk menghindari kehamilan akan tetapi apabila terjadi kehamilan di sarankan untuk melakukan prenatal check up dengan kardiologi setiap bulan atau 2 bulan sekali. ${ }^{8}$ Perencanaan dan pelaksanaan merupakan hal yang penting bagi wanita hamil dengan penyakit jantung yang harus mencakupi penilaian risiko ibu dan janin, titrasi pemakaian obat jantung bila di perlukan, serial kunjungan selama masa kehamilan, perencanaan persalinan dan pencegahan serta pengobatan komplikasi. ${ }^{9}$

\section{Mortalitas Maternal dengan Penyakit Jantung Bawaan (PJB)}

Risiko komplikasi kardiovaskuler pada maternal dengan penyakit jantung kongenital tergantung dari tipe malformasi dan gangguan fungsional yang di hasilkan dalam aktivitas sehari-hari. Yang merupakan perhatian khusus pada maternal dengan penyakit jantung adalah dekompensasi kardiak yang di sebabkan oleh ketidak mampuan tubuh untuk memenuhi kebutuhan dari perubahan fisiologik pada kehamilan dan kelahiran. Infeksi, pendarahan dan tromboembolisme berkontribusi meningkatkan risiko komplikasi pada maternal yang sudah memiliki penyakit jantung. Prediktor risiko mortalitas maternal dengan penyakit jantung bawaan (PJB) pada tabel 4. Klasifikasi ini di formulasi oleh Clarks. ${ }^{10}$ Penting untuk mengerti efek dari perubahan fisiologis yang di sebabkan oleh kehamilan pada penyakit jantung secara spesifik supaya pasien dan dokter dapat merencanakan dan mengantisipasi komplikasi pada pasien tersebut. Hal ini harus di lakukan dengan cara tim multidisiplin dari berbagai macam spesialisasi yang mencakup tim obstetri, perinatology, anestesiologi, neonatologi, kardiologi, intensivist dan bedah

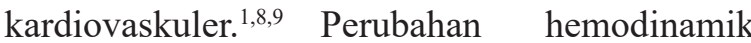
pada kehamilan menyebabkan tekanan pada fungsi kardiovaskuler. Akan tetapi sebagian dari 
Tabel 3. Kehamilan Beresiko menurut WHO

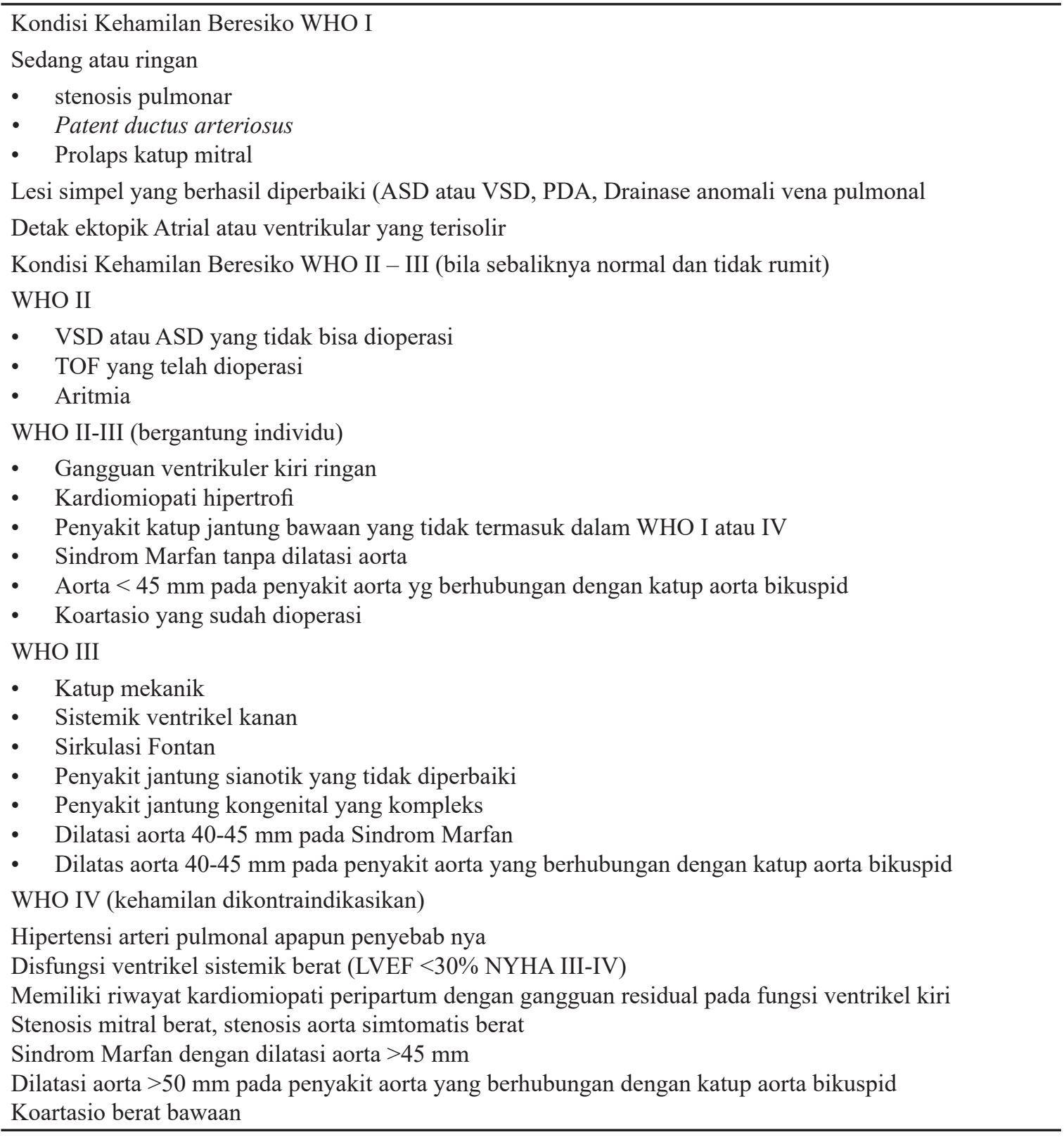

maternal dengan penyakit jantung akan tetap asimptomatik selama masa kehamilan dan dapat menjalani proses kehamilan, persalinan dan kelahiran secara baik. Akan tetapi pada pasien dengan gejala sesak nafas pada aktivitas seharihari ataupun pada saat istirahat contohnya pada NYHA kategori jekas III dan IV dan klasifikasi Clark group 2 dan 3 pada tabel di atas. Biasanya tidak dapat melalui kehamilan persalinan dan kelahiran tampa komplikasi. Oleh karena itu perencanaan pasca operasi seperti support ventilasi dan hemodinamik monitoring dan perencanaan operasi koreksi terhadap gangguan jantung dapat di rencanakan sebelum tindakan reversal dari anestesi dan ekstubasi.

\section{Simpulan}

Keberhasilan anestesi pada kehamilan adalah mengoptimalkan fungsi kardiovaskuler dan respirasi dengan memanipulasi hemodinamik sesuai target dan pemilihan teknik anestesi 
Tabel 4. Klasifikasi Clarks

\begin{tabular}{ll}
\hline Grup 1 & Mortalitas $<$ 1\% \\
& Defek Septum Atrium \\
& Defek Septum Ventrikel \\
& Patent Ductus Arteriosus \\
& Gangguan pulmonal/trikuspid \\
& TOF terkoreksi \\
& Katup bioprostetik \\
& Stenosis Mitral, NYHA kelas I dan II \\
& Mortalitas 5\%-15\% \\
Grup 2 & \\
Grup 2A & Stenosis Mitral, NYHA kelas III dan IV \\
& Stenosis Aortic \\
& Koartasi aorta tanpa keterlibatan katup \\
& TOF tidak terkoreksi \\
& Riwayat infark miokard \\
& Sindrom Marfan dengan aorta normal \\
& \\
Grup 3 & Kindral stenosis dengan Fbrilasi Atrium \\
& Katup buatan \\
& Mortalitas 25-50\% \\
Grup 2B & \\
& \\
& \\
&
\end{tabular}

yang sesuai pada pasien, melakukan monitor hemodinamik yang ketat, analgetik yang adekuat serta harus siap untuk melakukan resusitasi bila diperlukan. Prinsip menejemen anestesi obstetri adalah menjaga perfusi, uteroplacental dengan mencegah kompresi aortocava, meminimalisir blok simpatis dan menjaga kecukupan volume intravascular, lakukan monitoring yang ketatuntuk ibu dan fetus, pencegahan/propilaksis aspirasi.

\section{Daftar Pustaka}

1. European Society of Gynecology (ESG); Association for European Paediatric Cardiology (AEPC); German Society1)

Regitz-Zagrosek V, Lunquist CR, Borghi C, Cifkova R, Ferreira R, Foidart JM, et al. ESC Guidelines on the management of cardiovascular diseases during pregnancy: the Task Force on the Management of Cardiovascular Diseases during Pregnancy of the European Society of Cardiology (ESC). Eur Heart J. 2011. 32(24):3147-97.

2. Luthra A, Bajaj R, Jafra A, Jangra K, Arya $\mathrm{V} \mathrm{K}$. Anesthesia in pregnancy with heart diseases. Saudi J Anesth. 2017; 11(4): 45471.

3. Isngadi. Manajemen Anestesi pada kehamilan dengan penyakit Jantung. Malang: Universitas Brawijaya; 2017.

4. Baehner T, Ellerkmann RK. Anesthesia in adults with congenital heart disease. Curr Opin Anaesthesiol. 2017. 30(3):418-25.

5. Gottlieb EA, Andropoulos DB. Anesthesia for the patient with congenital heart disease presenting for noncardiac surgery. Curr Opin Anaesthesiol. 2013. 26(3): 318-26.

6. White MC, Peyton JM. Anaesthetic management of children with congenital heart disease for non-cardiac Surgery.Continuing Education in Anaesthesia, Critical Care \& Pain j. 2012.

7. Arendt KW, Lindley KJ. Obstetric anesthesia management of the patient with cardiac disease. Int J Obstet Anesth. 2019. 37, 73-85.

8. Lovell AT. Anaesthetic implications of grown-up congenital heart disease. $\mathrm{Br} \mathrm{J}$ Anaesth. 2004. 93 (1): 129-39.

9. Bishop L, Lansbury A, English K. Adult congenital heart disease and pregnancy. BJA Educ. 2018. 18(1): 23e29.

10. Rychik J, Atz AM, Celermajer DS, Deal BJ, Gatzoulis MA, Gewillig MH, et al. Evaluation and Management of the Child and Adult With Fontan Circulation: A Scientific Statement From the American Heart Association. Circulation. 2019. 140 (6): e234-e284. 